\title{
Amoxicillin Induced Behavioral Neurotoxicity and Histopathological Changes in Organs of Albino Rats
}

\author{
Sabita Paudel, ${ }^{1}$ Bijay Aryal, ${ }^{2}$ Sunita Ranabhat ${ }^{3}$ \\ ${ }^{1}$ Department of Pharmacology, Gandaki Medical College, Pokhara, Nepal, ${ }^{2}$ Department of Pharmacology Karnali \\ Academy of Health Sciences, Jumla, Nepal, ${ }^{3}$ Department of Pathology Gandaki Medical College, Pokhara, Nepal.
}

\begin{abstract}
Background: There are various adverse drug reactions of penicillin. Neurotoxicity is attracting the attention of researchers all over the world. It also affects other organs like liver, kidney, heart and testes.

Methods: The study was conducted at pharmacy and pharmacology department of Gandaki Medical College (GMC) from January till April, 2018. Albino rats were divided six each in test and control group. Tests were administered amoxicillin $90 \mathrm{mg} / \mathrm{kg} / \mathrm{d}$ and control with distilled water for 10 days. After 10 days, rats were tested for neurotoxicity with Rota-rod (RR) and modified forced swim test (MFST). They were then sacrificed under anesthesia, organs were dissected and sent for histopathological investigation.
\end{abstract}

\begin{abstract}
Results: The latency to fall from RR apparatus decreased (150.9s) in test rats than control (8.2). In MFST, immobility time was increased than control. Swimming time (ST) was decreased and climbing time (CT) was not significantly altered in test rats than control. Brain of test rats (TR) showed shrunken neurons surrounded by perineuronal vacuolations, liver and kidney showed degenerative changes. Vacuolations and pyknotic cells were seen in spermatogenic cells.
\end{abstract}

Conclusions: Neurotoxic effects were seen in TR which recommends regulation of the administration of high dose of penicillin.

Keywords: Amoxicillin; histopathology; Modified Forced Swim Test; Rotarod test.

\begin{abstract}
INTRODUCTION
Antibiotics are lifesaving drugs in infections. They are categorized broadly into cell wall inhibitors, protein synthesis inhibitors and enzyme inhibitors. Amoxicillin belongs to cell wall inhibitors group of antibiotics. It is one of the widely prescribed antibiotics. It has adverse effects like diarrhea, hepatotoxicity and hypersensitivity. Along with these, recent findings have presented various effects in brain, heart, kidney and testes. ${ }^{1-3}$ Neurotoxic effects like depression, confusion, disorientation, somnolence, twitching, myoclonus, generalized tonic clonic seizures, status epilepticus were evidenced in different studies. ${ }^{4-8}$ The first three are well known adverse events whereas neurotoxicity is the recent finding. ${ }^{9-11}$
\end{abstract}

Histopathologically, brain cells show pyknotic nuclei with perineuronal vacuolations, hepatocytes depict hemorrhages and renal tubules show degeneration. In the testes, there is the reduction in spermatogenesis. On administration of the drug for 10 to 14 days in high dose, these adverse effects are more prominent. ${ }^{2}$ This study evaluates the neurotoxic adverse effects of amoxicillin like epilepsy and depression in albino rats. The histopathological changes in the organs after the administration of the drug were studied.

\section{METHODS}

This study was conducted at the pharmacy, pharmacology and pathology department of GMC in the period of four months from January till April, 2018. Six test and six control albino rats of 200 to $220 \mathrm{gm}$ weight were the subjects of study. They were purchased from Department of Plant Resources, Kathmandu, Nepal. They were kept under $12 \mathrm{~h}$ day and $12 \mathrm{~h}$ night cycle. Temperature was $(25 \pm 3) \quad$ C with relative humidity of $50 \% \pm$ $15 \%$. Amoxicillin was administered at the dose of $90 \mathrm{mg} / \mathrm{kg} / \mathrm{d}$. It was administered once daily through oral gavage at 10 am for 10 days. Food and water were provided ad libitum.

Rotarod test was done to observe the neuromuscular control. This apparatus was manufactured by Indosati, Scientific Lab Equipment. Laboratory animals, like rat grasp the rod firmly with their paws. As rod rotates, latency to fall from rotating rod was noted. Revolutions were set at $5 \mathrm{rev} / \mathrm{m} .{ }^{13}$

Correspondence: Dr. Sabita Paudel, Department of Pharmacology, Gandaki Medical College, Pokhara, Nepal. Email: drsabitapaudel@gmail.com. Phone: +977-9846521128. Article received: 2019-08-18. Article accepted: 2020-02-16. 
Paudel et al. Amoxicillin Induced Behavioral Neurotoxicity and Histopathological Changes..

MFST apparatus was purchased from Indosati, Scientific Lab Equipments. This test was first described by Porsolt. It was conducted to observe depression in laboratory animals like rat, mice. It consisted of plexiglass measuring $50 \mathrm{~cm}$ in height and a diameter of $20 \mathrm{~cm}$. Water at room temperature is kept till $45 \mathrm{~mm}$ depth. Pre-training trial was conducted for 24 hours before test trial. Rat was allowed to swim for five minutes each in both trials. Climbing, swimming and immobility times were noted in a five minutes' time. Climbing means state where quick movements of the forelimbs are observed such that the front paws break the surface of the water.

Swimming means if movement of forelimbs or hind limbs in a paddling fashion is observed. Immobility means the floating with the absence of any movement except for those necessary for keeping the nose above water. ${ }^{14}$ After 24 hours of last administration of AMX, training sessions were conducted for RR and MFST. Then, rats were sacrificed under diazepam and ketamine anesthesia. Dissection was done with universal precautions. Samples of brain, two kidneys, two testes and all lobes of liver were collected and kept in phosphate buffer to transport to histopathology lab. The samples were then fixed with $10 \%$ formalin solution. They were cut into 4-5 $\mu \mathrm{m}$ thick sections and slides prepared with hematoxylin and eosin stain. Microscopic studies were done under high power field.

\section{RESULTS}

The test rats suffered from chronic diarrhea after $2^{\text {nd }}$ day of administration of medication till sacrifice. The latency to fall from RR apparatus decreased significantly in test rats than control. In MFST, immobility time was significantly increased than control. Swimming time was decreased significantly and CT was not significantly altered in test rats than control (Table 1).

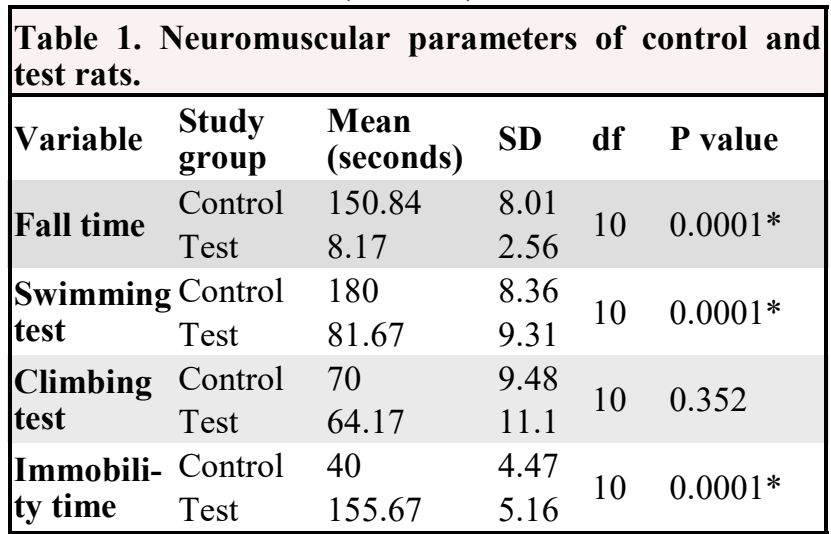

The liver function test showed significant elevation of liver enzymes, AST and ALT. Urea and creatinine were higher in test rats than the control but there was no statistically significant increment
(Table 2).

\begin{tabular}{|llllll|}
\hline $\begin{array}{l}\text { Table 2. } \\
\text { test rats. }\end{array}$ & Laboratory & parameters of the control and \\
\hline Variable Study group & $\begin{array}{l}\text { Mean } \\
\text { value (U) }\end{array}$ & SD & df & P value \\
AST & $\begin{array}{l}\text { Control } \\
\text { Test }\end{array}$ & 186.17 & 15.5 & 10 & $0.049^{*}$ \\
& 207.5 & 17.5 & 10 & \\
ALT & Control & 63 & 6.81 & 10 & $0.001^{*}$ \\
& Test & 103.27 & 5.14 & & \\
Urea & Control & 32 & 4.69 & 10 & 0.092 \\
Creati- & Control & 37 & 4.6 & & \\
nine & Test & 0.58 & 0.07 & 10 & 0.072 \\
\hline
\end{tabular}

\section{Histopathological changes}

Histopathological investigation of liver of control rats showed normal picture. Test rats showed degenerated hepatocytes and extravasation of RBC. Brain of $\mathrm{CR}$ showed cortical arrangement of neurons and that of TR showed shrunken neurons surrounded by perineuronal vacuolations. Testes of $\mathrm{CRs}$ picturized normal spermatocytes and spermatogenesis. TRs were having mild degenerative changes in the spermatogenic cells. There were vacuolations and pyknotic cells. The glomerulus, urinary space, Bowman's capsule, proximal and distal convoluted tubules were normal in histopathology of control rats. In test rats, there were severe degenerative changes in glomerulus and widening of urinary space with hemorrhage between tubules. The histopathological changes are shown in pictures from Figure no. 3 to 6 . The figures $3 a, 4 a, 5 a$ and $6 a$ are from the control rats and those of $3 b, 4 b, 5 b$ and $6 b$ are from the test rats.

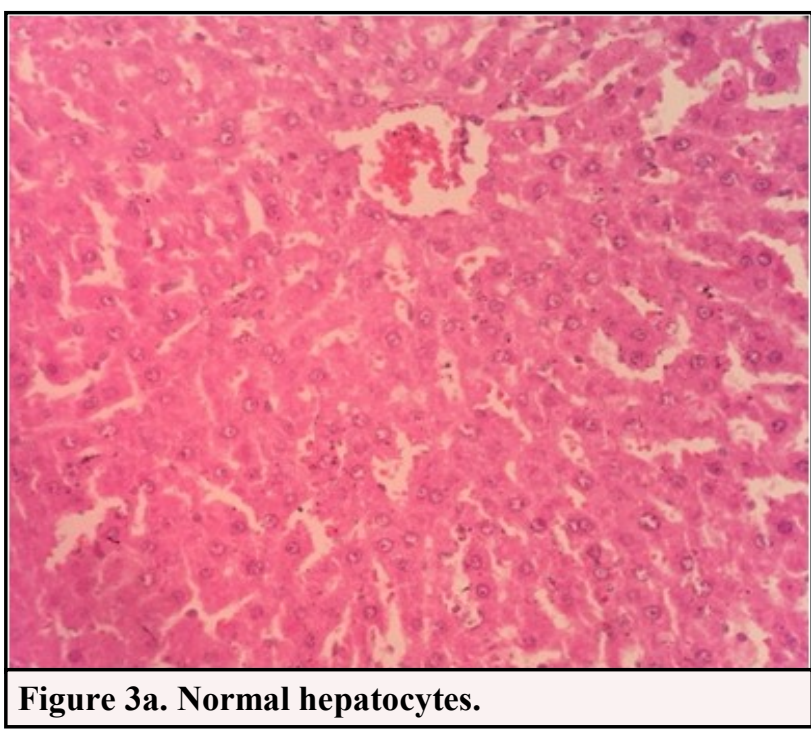

\section{DISCUSSION}

Amoxicillin brought several changes in various organs of albino rats in our study. This suggested the careful usage of the antibiotic and the monitoring of dosage and limitation of prescription 
Paudel et al. Amoxicillin Induced Behavioral Neurotoxicity and Histopathological Changes..
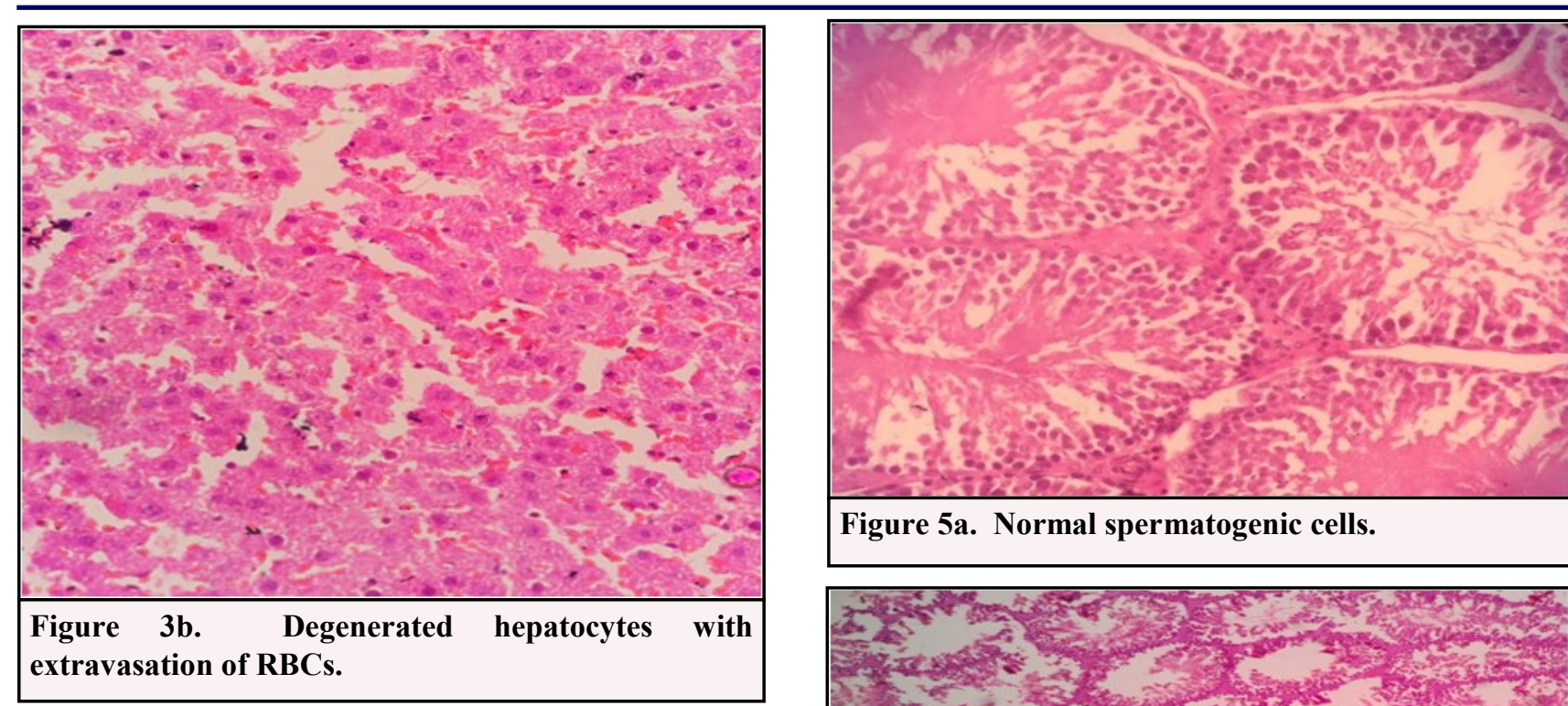

Figure 5a. Normal spermatogenic cells.

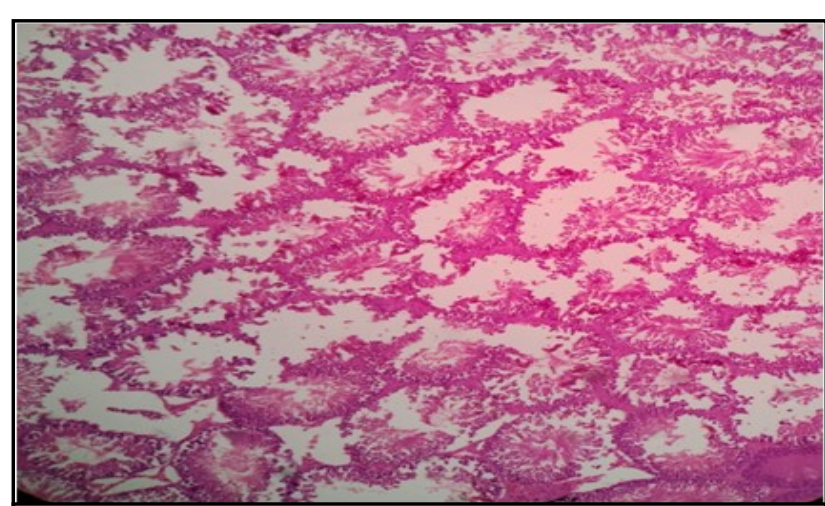

Figure 5b. Mild degenerative changes in the spermatogenic cells, vacuolation and pyknotic cells.

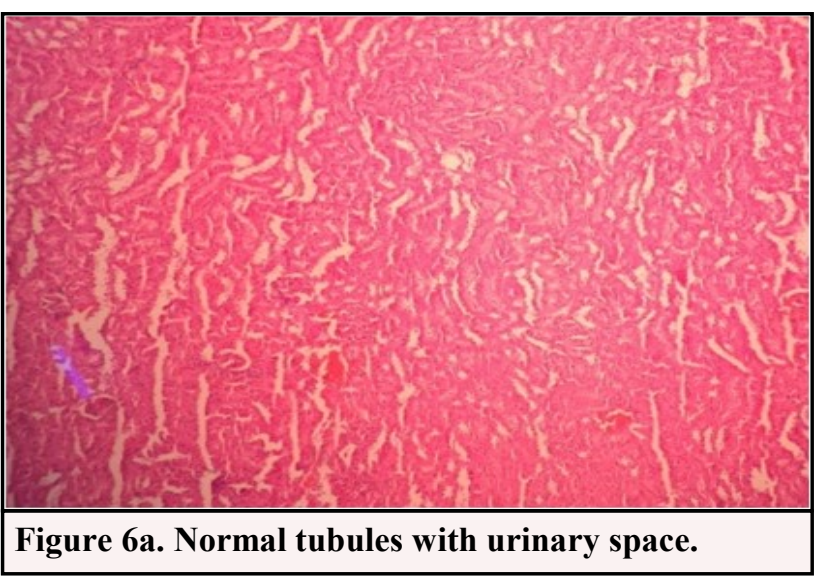

Figure 4a. Normal neurons and nuclei.

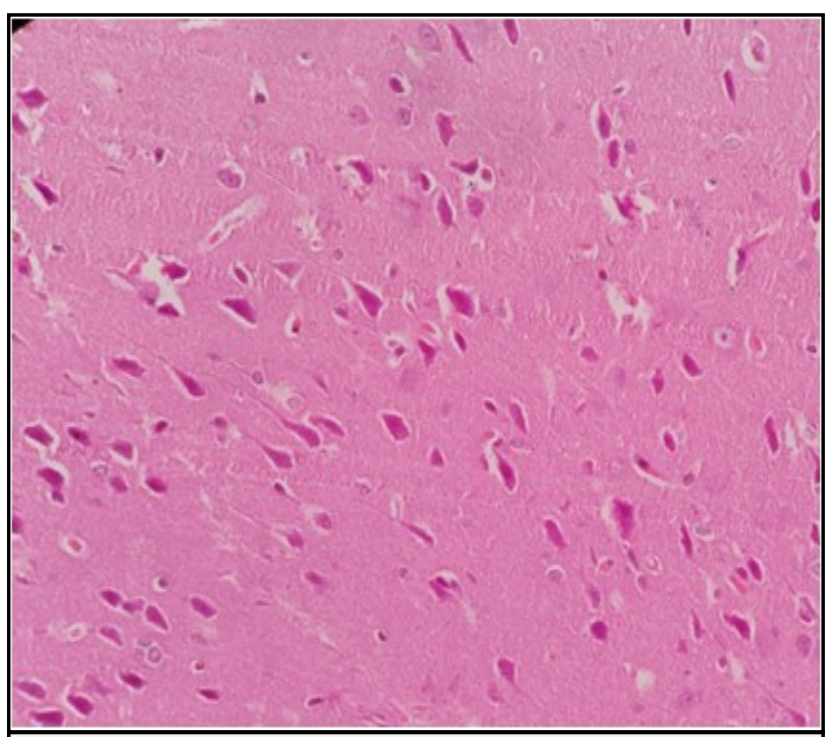

Figure 4b. Shrunken nuclei and perineuronal vacuolation.

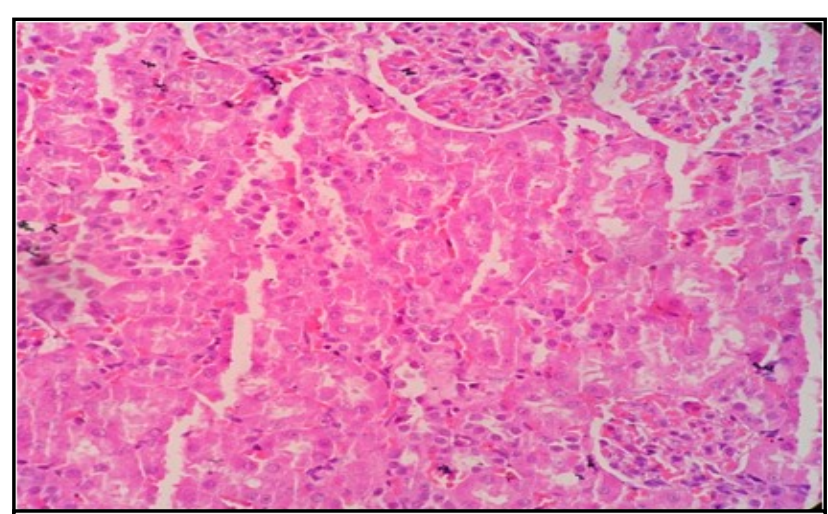

Figure 6b. Degenerative changes in glomerulus and widening of urinary space with hemorrhage between tubules. 
for long duration. Diarrhea is one of the adverse effects of amoxicillin. It is due to suppression of normal flora of gut. ${ }^{1}$ Rotarod test was discovered to check motor coordination in laboratory animals. ${ }^{13}$ The falling time from RR apparatus was decreased in test rats due to motor incoordination in test rats. In epileptic rats, motor coordination was weak. This decreased grasp of rats to rod and decreased fall time. In our study, falling off time was decreased in test rats than control similar to other studies. ${ }^{12}$

The $\beta$-lactam ring structure shares structural similarities with GABA. AMX interferes with GABA action and reduces GABA mediated inhibition of inward chloride current. This results in enhanced excitatory neurotransmission which predisposes to epileptiform discharges. ${ }^{10,15}$ Epileptogenic properties of AMX was first described by Johnson and Walker in 1945 AD. ${ }^{16-20}$

Increase in IT and decrease in ST indicated depressive behavior in test rats. Depressive rats had decreased fear of drowning. So, they didn't swim and remained immobile in water for longer time. CT was not significantly altered in both groups. Finding of study done by Atli et al. ${ }^{21}$ suggested that serotonin level was decreased in AMX treated rats.

\section{REFERENCES}

1. Brinton L, Chabner B, Knollman B. Goodman and Gilman's The Pharmacological Basis of Therapeutics. 12th ed. New York: Mc GrawHill Education; 2011.

2. Katzing BG, Trevor AJ. Basic and Clinical Pharmacology. 13th ed. New York: McGrawHill Education; 2015.

3. Tripathi KD. Essentials of Medical Pharmacology. 8th ed. New Delhi: Jaypee Brothers; 2018.

4. Smith H, Lerner PI, Weinstein L. Neurotoxicity and "massive" intravenous therapy with penicillin: a study of possible predisposing factors. Arch Intern Med. 1967;120:47-53. https://doi.org/10.1001/archinte.120.1.47

5. Lerner PI, Smith H, Weinstein L. Penicillin neurotoxicity. Ann N Y Acad Sci. 1967;145:310-8. https://doi.org/10.1111/j.17496632.1967.tb50228.x

6. Schliamser SE, Cars O, Norrby SR. Neurotoxicity of beta-lactam antibiotics: predisposing factors and pathogenesis. J Antimicrob Chemother. 1991;27:405-25. https://doi.org/10.1093/jac/27.4.405

7. Anonymous. Penicillin, ceftazidime, and the epilepsies. Lancet. 1992;340:400-1. https:// doi.org/10.1016/0140-6736(92)91476-O

8. Mattappalil A, Mergenhagen KA. Neurotoxicity with Antimicrobials in the Elderly : A Review. Clinical Therapeutics. 2014;36(11):1489-511. https://doi.org/10.1016/j.clinthera.2014.09.020
Serotonergic system was responsible for swimming behavior. Whereas, climbing time was same as dopamine and noradrenaline level wasn't significantly altered.

Liver enzymes were increased due to pathologic changes in liver. ${ }^{22}$ TRs showed degenerated hepatocytes due to drug injury. Drug induced liver injury is one of the major problems with antibiotics. ${ }^{23}$ AMX forms hepatocellular lesions. These lesions progresses to cirrhosis in its severe form. ${ }^{24}$ There was extravasation of RBCs. The brain showed shrunken neurons surrounded by perineuronal vacuolations. Testes were having mild degenerative changes in the spermatogenic cells. There were vacuolations and pyknotic cells. There were severe degenerative changes in glomerulus and widening of urinary space with hemorrhage between tubules. These findings were similar to finding obtained by Fahmy et al. in Egypt. ${ }^{11}$

\section{CONCLUSIONS}

Amoxicillin had shown neurotoxic effects like convulsion and depression in albino rats. The effects in testes as well as other organs were also seen. Therefore, it needs special precautions when prescribing.

9. Chow KM, Hui AC, Szeto CC. Neurotoxicity induced by beta-lactam antibiotics: from bench to bedside. Eur J Clin Microbiol Infect Dis. 2005;24:649-53. https://doi.org/10.1007/ s10096-005-0021-y

10. Bhattacharyya S, Darby R, Berkowitz AL. Antibiotic-Induced Neurotoxicity. Curr Infect Dis Rep. 2014;16:448. https://doi.org/10.1007/ s11908-014-0448-3

11. Grill MF, Maganti RK. Neurotoxic effects associated with antibiotic use: management considerations. Br J Clin Pharmacol. 2011.72 (3):381-93. https://doi.org/10.1111/j.13652125.2011.03991.x

12. Fahmy MA, Farghaly AA, Omara EA, Hassan ZM, Aly FAE, Donya SM, et. al. Amoxicillinclavulanic acid induced sperm abnormalities and histopathological changes in mice. Asian Pac J Trop Biomed. 2017;7(9):809-16. https:// doi.org/10.1016/j.apjtb.2017.08.002

13. K Pritchett, GB Mulder. The Rotarod. Journal of the American Association for Laboratory Animal Science. 2003;42(6):49

14. Yankelevitch-Yahav, R., Franko, M., Huly, A., Doron, R. The Forced Swim Test as a Model of Depressive-like Behavior. J Vis Exp. 2015; (97):1-7 e52587. https://doi.org/10.3791/52587

15. DeLorey TM, Olsen RW. $\gamma$-aminobutyric acidA receptor structure and function. J Biol Chem. 1992;267:16747-50.

16. Walker AE, Johnson HC, Kollros JJ. Penicillin convulsions: the convulsive effects of penicillin 
applied to the cerebral cortex of monkey and man. Surg Gynecol Obstet. 1945;81:692-701.

17. Johnson HC, Walker AE. Intraventricular penicillin. JAMA. 1945;27:217-9. https:// doi.org/10.1001/jama.1945.92860040001007

18. Walker AE, Johnson HC. Convulsive factor in commercial penicillin. Arch Surg. 1945;50:6973. https://doi.org/10.1001/ archsurg. 1945.01230030074003

19. Niedermeyer EA, Walker E. Neurosurgeon, neuroscientist, and epileptologist. Epilepsia. 1995;36:516-21. https://doi.org/10.1111/j.15281157.1995.tb00495.x

20. Sarro AD, Ammendola D, Zappala M, Grasso S, Sarro GBD. Relationship between Structure and Convulsant Properties of Some b-Lactam Antibiotics following Intracerebroventricular Micro injection in Rats. Antimicrobial agents and Chemotherapy. 1995;39(1):232-7. https:// doi.org/10.1128/AAC.39.1.232
21. Atli O, Demir-Ozkay U, Ilgin S, Aydin TH, Akbulut EN, Sener E. Evidence for neurotoxicity associated with amoxicillin in juvenile rats. Human and Experimental Toxicology. 2015:1-11. https:// doi.org/10.1016/j.toxlet.2015.08.784

22. Bhaskar RK, Kurup GM. Biochemical marker studies of acute drug induced liver injury in rat.

23. Journal of Technological Advances \& Scientific Research. 2015;1(4):332-7

24. Gayam V, Khalid M, Shrestha B, Hossain MR, Dahal S, Garlapati P,et al. Drug-Induced Liver Injury: An Institutional Case Series and Review of Literature. Journal of Investigative Medicine High Impact Case Reports. 2018;(6): 1-7. https://doi.org/10.1177/2324709618761754

25. Jordan T, Gonzalez M, Casado M, Suarez JF. Amoxicillin clavulanic acid induced hepatotoxicity with progression to cirrhosis. Gastroenterol Hepatol. 2002;25(4):240-3.

Citation: Paudel S, Aryal B, Ranabhat A. Amoxicillin Induced Behavioral Neurotoxicity and Histopathological Changes in The Organs of Albino Rats. JCMS Nepal. 2020; 16(1):12-6. 